FEATURE

Damon Wingfield and Philip Gooding

Office for National Statistics

\section{CPI and RPI: the 2008 basket of goods and services}

- applying a fixed set of weights to price changes for each of the items such that their influence on the overall index reflects their importance in the typical household budget

the consumer prices index (CPI) and retail prices index (RPI) are representative of consumer spending patterns, the items that are priced in compiling the indices are reviewed each year. This article describes the review process and explains how and why the various items in the CPI and RPI baskets are chosen. The contents of the CPI and RPI baskets for 2008 are summarised in Annexes A and B of the full article, which can be downloaded from the National Statistics website at www.statistics.gov.uk /cci/ article. asp? $\mathrm{id}=1951$

The main changes from the 2007 price collection are discussed. Similar articles have been published in previous years. This article also describes two changes to the methodology used to compile the CPI and RPI. These relate to the measurement of gas and electricity, and fresh fruit and vegetable prices. only changes in prices, and not ongoing
T he most useful way to think about both the consumer prices index (CPI) and retail prices index (RPI) is to imagine a shopping basket containing those goods and services on which people typically spend their money. As the prices of the various items in the basket change over time, so does the total cost of the basket. Movements in the CPI and RPI indices represent the changing cost of this representative shopping basket.

In principle, the cost of the basket should be calculated with reference to all consumer goods and services purchased by households, and the prices measured in every shop or outlet that supplies them. In practice, both the CPI and RPI are calculated by collecting a sample of prices for a selection of representative goods and services in a range of UK retail locations. Currently, around 120,000 separate price quotations are used every month in compiling the indices, covering some 650 representative consumer goods and services for which prices are collected in around 150 areas throughout the UK.

Within each year, the RPI and CPI are described as fixed-quantity (Laspeyrestype) price indices; they represent the changing cost of a basket of goods and services of fixed composition, quantity and quality. In practice, this is achieved by:

- holding constant through each year the sample of representative goods and services for which prices are collected each month in estimating price changes more generally, and
In this way, changes in the RPI and CPI indices from month to month reflect variations in consumer purchasing patterns.

However, the contents of the RPI and CPI baskets of goods and services and their associated expenditure weights are updated annually. This is important in helping to avoid potential biases in consumer price indices that might otherwise develop over time. These might include the development of entirely new goods and services, or the tendency for consumers to substitute purchases away from those particular goods and services for which prices have risen relatively rapidly. For instance, if tea showed a dramatic rise in prices during one year, consumers might switch their spending towards other beverages, making it necessary to adjust the expenditure weights accordingly in the following year.

These procedures also help to ensure that the indices reflect longer-term trends in consumer spending patterns. For example, the proportion of household expenditure devoted to household services has risen steadily over the last 20 years. This is reflected both in an increasing weight for this component in the CPI and RPI, and the addition of new items in the basket to improve measurement of price changes in this area: examples include internet 
subscriptions, and playgroup and nanny fees.

For the RPI, changes to the items and weights are introduced in the February index each year, but with an overlapping collection of prices in January. This means that the figures for each year can be 'chainlinked' together to form a long-run price index spanning many years. This procedure ensures that the annual changes to the basket and weights have no impact on estimated changes in prices as measured by the indices. The same basic approach is likewise adopted in the CPI although, for technical reasons, it is necessary to chainlink the published index twice each year rather than only once as in the RPI. ${ }^{1}$

ONS (2004) provides a helpful introduction to the concepts and procedures underpinning the compilation of the CPI and RPI indices. These are described in much greater detail in ONS (2007).

\section{Representative items}

It would be both impractical and unnecessary to measure price changes of every item bought by every household in compiling the CPI and RPI. There are some individual goods and services where typical household expenditure is sufficiently large that they merit inclusion in the basket in their own right; examples include school fees, petrol, telephone charges, and electricity and gas supply.

However, more commonly, it is necessary to select a sample of specific goods and services that can give a reliable measure of price movements for a broader range of similar items. For example, price changes for garden spades might be considered representative of price changes for other garden tools. These are called representative items. The selection of these representative items is purposive or judgemental; the significant difficulties involved in defining an adequate sampling frame, that is, a list of all the individual goods and services bought by households, restricts the use of traditional random sampling methods when choosing the representative items.

For each product grouping, a number of items are selected for pricing whose price movements, taken together, will provide a good estimate of the overall change in prices for the group as a whole. For example, there are around 20 representative items in the CPI 'furniture and furnishings' class, from bedroom wardrobes to kitchen units, for which prices are collected each month to give an overall estimate of price changes for all furniture products. The same approach is adopted in the RPI, although the product classification systems used in each case do differ. ${ }^{2}$

The prices collected for each product group are then combined to produce the overall CPI and RPI indices, with weights proportional to total expenditure on the entire product group. So the weight given to 'furniture and furnishings' in the CPI shopping basket, or 'furniture' in the RPI basket, will reflect average household spending on all furniture products as opposed to expenditure only on those items that have been chosen to represent the group. Similarly, the weight of garden spades would be derived from all spending on garden tools.

As described above, these weights are also updated annually so that the indices reflect current spending patterns. In line with usual practice, CPI class weights were updated with effect from the January 2008 index, and RPI section weights with effect from the February 2008 index, at which point the weights for the more detailed (unpublished) item indices were also revised. A brief comparison of high-level RPI weights since 1987 is shown later in this article, including the new weights for 2008. A more detailed article on changes to the published CPI and RPI weights will be published on the National Statistics website in April 2008.

Note also that there are some specific differences in the commodity coverage of the CPI and RPI indices. For example, the RPI basket includes a number of items chosen to represent owner-occupier housing costs, including mortgage interest payments and depreciation costs, all of which are excluded from the CPI. These differences are described in greater detail in Roe and Fenwick (2004). Beyond these specific areas, the contents of the CPI and RPI baskets are very similar, although the precise weights attached to the individual items in each index do differ. ${ }^{3}$

\section{Selecting the representative items}

A number of factors need to be taken into account when choosing representative items. Of course, the items must be easy to find by price collectors, so ensuring that estimates of price change are based on an adequate number of price quotes collected throughout the UK. Since the CPI and RPI are based on the cost of a fixed in-year basket of goods and services, ideally they should also be available for purchase throughout the year. However, availability of some food and clothing items is clearly seasonal, and so these goods require a slightly different treatment in the indices.

The number of items chosen to represent each product group within the CPI and RPI depends both on the weight (expenditure) of the group and also the variability of price changes between the various items that could be selected to represent the group (reflecting, for example, the diversity of products available). Intuitively, it makes sense to choose more items in product groups where spending is high; this helps to minimise sampling variability in the estimate of price change for high-weighted groups, and therefore in the overall price index. However, if price movements of all possible items in the group are very similar, it is sufficient to collect prices for only a few. ${ }^{4}$ By contrast, if price movements of all the possible items are very different, prices will be needed for many representative items to get a reliable overall estimate of price change for the group.

Following from this, analysis of the balance in the allocation of items to broad commodity groupings, as presented for the 12 divisions of the CPI in Table $\mathbf{1}$, acts as a useful anchor for the annual review of the basket. The significant allocation of items to the food division relative to its index weight, for example, is partly explained by the relatively high variation in observed price changes between the individual goods in this area. Conversely, a smaller proportion of items relative to index weight is allocated to the restaurants and hotels division, reflecting greater similarity in observed price changes. In some cases, such as transport and housing, apparent low allocations of items are explained by the presence of some dominant individual items, for example, car purchase or housing rents. Abstracting from these, the case for adding further items to improve coverage of these divisions' remaining index weights is much weaker - instead, it is far more important to ensure that the sampling of prices for these heavily weighted items is as comprehensive as possible.

The analysis also helps to highlight those areas of the index which might benefit most from improved coverage, such as miscellaneous goods and services. The current allocation of items to the division is broadly comparable to its index weight, but variation in price changes appears relatively high, possibly reflecting the diversity of goods and services covered by this division. As discussed later, this has motivated some of the changes to the basket introduced in 2008. Conversely, it also helps to highlight areas where there is scope to remove items 
Table 1

\section{Allocation of items to CPI divisions in 2008}

\begin{tabular}{lrrr}
\hline & $\begin{array}{r}\text { CPI weight } \\
\text { (per cent) }\end{array}$ & $\begin{array}{r}\text { Observed } \\
\text { variation in } \\
\text { price changes }\end{array}$ & $\begin{array}{r}\text { Representative } \\
\text { items }{ }^{2} \text { (percentage } \\
\text { of total) }\end{array}$ \\
\hline Food and non-alcoholic beverages & 10.9 & High & 22 \\
Alcohol and tobacco & 4.2 & Low & 4 \\
Clothing and footwear & 6.3 & Medium & 11 \\
Housing and household services & 11.5 & Medium & 5 \\
Furniture and household goods & 6.7 & Medium & 11 \\
Health & 2.2 & Low & 3 \\
& 15.2 & High & 6 \\
Transport & 2.3 & Low & 1 \\
Communication & 15.2 & High & 17 \\
Recreation and culture & 1.9 & Low & 1 \\
Education & ${ }^{3}$ & Low & 8 \\
Restaurants and hotels & 13.7 & High & 11 \\
Miscellaneous goods and services & 9.9 & & \\
\hline
\end{tabular}

\section{Notes:}

1 Based on an analysis of variation in price changes between the individual items chosen to represent each division in the period 1999 to 2003.

2 These figures should be treated as providing only a broad indication of the allocation of items to the $12 \mathrm{CPI}$ divisions. For example, the sample of prices underpinning an existing item might easily be stratified in some way to form two or more distinct items; conversely, items could be merged to form a single item representing a wider, more heterogeneous, spending category. See footnote 3 for specific example.

3 The item 'University tuition fees' is classified as one separate item, but the index takes into account prices for several hundred courses, including undergraduate, postgraduate and part-time.

from the basket without any significant loss of precision in the indices. It is important that growth in the overall size of the basket is limited each year so that production costs and processing times may be contained.

Such analysis, of course, cannot indicate which items should be priced, and so choosing a particular set of items to represent each area remains a matter of judgement. CPI and RPI commodity groupings are regularly reviewed with the aim that all significant items or distinct markets where consumers' expenditure exceeds around $£ 400$ million annually are explicitly represented in the basket, except where those items are judged to be adequately represented by other items in the basket. ${ }^{5}$ Conversely, where spending on items falls below the $£ 100$ million mark, there should be good reason for their continuing inclusion in the basket. For example, while spending on acoustic guitars and power drills is relatively low, both are included in the basket to represent wider markets (musical instruments and electrical tools, respectively) that would otherwise not be covered explicitly. Trends in expenditure, as well as the latest available figures, help to inform the decisions in all cases.

This focus on relative expenditures in determining the contents of the basket partly reflects the wealth of data that is available describing household spending patterns. One major source of information comes from the diaries and questionnaires filled in by people taking part in the ONS Expenditure and Food Survey, a continuous survey of over 6,000 households each year. This is supplemented by detailed analyses of trends presented by market research companies, trade journals and in press reports. Changes in the retail environment are also reported to ONS by the price collectors and, together, these various sources of information help to ensure that the goods and services the average household spends its money on are appropriately represented in the CPI and RPI baskets.

It is very important to note that the contents of the basket and, in particular, changes from one year to the next, should not be accorded significance beyond their purpose as representative items used in estimating retail price changes. Changes to the basket will reflect evolving consumer tastes, but only over a long run of years. In any particular year, changes to the basket will reflect a range of considerations such as practical experience in collecting prices, the desire to improve coverage in highspending areas, or analysis that suggests that estimated price changes could be improved at the margin by varying the number or type of representative items collected.

Indeed, within each product grouping, there is usually a point at which the exact number, choice of items and the precise weights attached to them becomes a matter of relatively fine judgement. At this detailed level, it is unlikely that such choices would have any significant impact on the CPI and RPI indices. For example, a selection of specific household appliances has been chosen to represent spending on small electrical goods, including irons and kettles. However, other representations would clearly be possible and equally valid.

Although the process for the 2008 basket review has been similar to those conducted in previous years, fewer changes are being made to the basket as the focus has been slightly different for two main reasons:

- when considering changes to the basket for 2008, extra attention was given to where and how price quotes for existing items are collected. Where suboptimal sampling techniques or problems existed with collection for an item, resources were dedicated towards those items. For example, class 12.1.2, appliances and products for personal care, was identified as one such area. Although no items within this class have changed for 2008 , the range of shops for certain items has been broadened, and the number of prices collected increased to attempt to reduce the volatility that frequent half-price sales for certain items within this class can have. Similarly, for class 5.1.1, furniture and furnishings, it was recognised that the retailing sales and recovery cycles for furniture were becoming more dramatic, with less than half-price sales commonplace. To attempt to reduce the impact of any one shop, the sampling of each item was reviewed and, in 2008, additional outlets have been added to the collection, and

- existing item descriptions have also been a particular focus. For example, a thorough review of existing item descriptions in the light of coverage the number of non-zero prices collected as a proportion of those attempted to be collected - for each item has been reviewed. In some cases, this has revealed that the item description specification is so narrow as to preclude certain varieties or supermarket own-brands

None of these points should undermine the basket review, however. Changes where spending demands inclusion/exclusion from the basket are being made, along with refinements to existing item descriptions or sampled outlets.

Finally, it should also be noted that the vast majority of 650 or so representative items remains unchanged in 2008. 
Table 2

Additions to the basket in 2008

\begin{tabular}{|c|c|c|c|}
\hline CPI class & RPI section & New item & Notes \\
\hline $\begin{array}{l}\text { 01.2.2 Mineral waters, } \\
\text { soft drinks and juices }\end{array}$ & 2120 Soft drinks & Pure fruit smoothie & $\begin{array}{l}\text { New item. Introduced to represent distinct and emerging market } \\
\text { and diversify range of soft drinks collected. }\end{array}$ \\
\hline 01.1.7 Vegetables & 2125 Fresh vegetables & Peppers & $\begin{array}{l}\text { New item. Introduced to increase number of fresh vegetables } \\
\text { prices collected. Although spending does not demand that peppers } \\
\text { be included in the basket, vegetable prices vary greatly so it is } \\
\text { beneficial to collect across as broad a range of items as possible. } \\
\text { Previously in the basket (as green pepper), removed in late 1990s. }\end{array}$ \\
\hline
\end{tabular}

01.1.6 Fruit

2127 Fresh fruit

Small-type oranges

11.1.1 Restaurants and cafes

2201 Restaurant meals

Muffin

02.1.3 Beer

3102 Beer off-sales

5203 Personal services

(not elsewhere classified)

09.1.4 Recording media

6302 CDs and tapes

6303 Toys, photographic

and sports equipment

6402 Entertainment and

other recreation
20 bottles lager (4.3-7.5\%)

Flower bouquet, next day delivery

Non-chart CD album

Portable digital storage device

Livery charges

New item. Can take various forms, for example, clementines and mandarins. As with peppers (see above), spending does not demand inclusion, but fruit prices are volatile and so it is beneficial to collect across a broad range of items.

New item. While beverages from coffee shops and bakeries are adequately represented in the basket already, a snack item is also being included from 2008 in the shape of the muffin. This is to represent spending on all such snacks (such as croissants and cakes) that are typically bought with a coffee. Prices collected will be for 'eat-in' wherever possible.

Replaces 'stubbies' item, to be collected from supermarkets and some off-licences only. Stubbies have become an increasingly difficult item to collect and monitor due to range of sizes and alcohol content. Whereas previously much supermarket space was devoted to stubbies, it has now switched to full size $(330 \mathrm{ml})$ bottles of lager.

Replaces long standing 'Red rose to Watford' item. This replacement represents changes in flower delivery over recent years and is a cost saving. A limited number of companies, so currently offer delivery, with price independent of region rather than collect these throughout the country, it makes sense to collect directly from the main companies.

New item. Introduced to split high weight of CD albums (chart CD album item remains in basket). Will represent purchase of 'classic' albums, prices for which may change differently from those for chart CDs.

New item. Represents growing market for all forms of portable storage, including camera memory cards, sticks etc, those used in mobile telephones and USB memory 'keys', typically used in personal computers.

New item in the basket for 2008. Improves coverage of an underrepresented class in CPI and represents a distinct market not currently represented.

- furniture and furnishing (5.1.1), with price collectors visiting an increased number of stores and several hundred more prices collected throughout the country for existing items

- other appliances and products for personal care (12.1.2), with more prices collected for existing items in the field, especially for electric razors and hair dryers existing sample of representative items across the CPI highlighted a need to improve coverage of price changes for a number of CPI classes. These areas include: and Table 3, together with a brief summary of the motivation for these changes. As the tables make clear, these motivations are diverse. As in previous years, changes to the basket in 2008 should certainly not
- analysis of the broad balance of the

be viewed as a simple indicator of those or services whose popularity has past year. Note that all of the changes to the basket in 2008 affect both the CPI and The following bullet points give a brief summary and explanation of the themes behind the changes to the basket for 2008 : gain at the same time next year.

New additions to the basket in 2008 and those items removed are set out in Table 2

\section{areas include:}


such goods. For example, pure fruit smoothies, introduced to represent the growing consumer demand for healthy crushed pure fruit drinks. In recent years, supermarkets have devoted an increasing amount of space to smoothies, as choice and, in turn, consumer spending have increased. The introduction of this item can also be seen to diversify the current sampling of fruit drinks - already the basket covers a wide range of fruit juice drinks, although nothing specifically targeting the smoothie

- as in most years, some of the new additions do represent developments in technology, illustrating evolving trends. In 2008, portable digital storage media is included for the first time - this item should not necessarily be seen as a direct replacement for the $35 \mathrm{~mm}$ camera film, as it covers far more than just camera memory cards. Aside from use in cameras to store photographs, portable storage media, in the form of various memory cards and USB storage sticks (all of which can be selected by price collectors), can give added functionality to portable music (mp3) players, games consoles, mobile telephones, transporting files between computers and so on. The market for digital storage has been growing steadily in recent years and the item now warrants inclusion in the basket

- as well as introducing items to represent distinct sectors or markets, a number of items have been introduced to diversify the range of products collected for already established items, usually where spending is significant. For example, a new non-chart pre-recorded CD has been introduced to supplement the existing CD item to better represent the high spending on CD albums. Similarly, new items in the form of peppers and small-type oranges (such as mandarins, satsumas and clementines) are added to fresh vegetables and fruit, respectively, in 2008. This is to increase the coverage of two classes with particularly high variability in prices

- in other cases, the new items are direct replacements for similar products that leave the basket in 2008. For example, large crates of regular sized (275-330ml) bottled lager replace the lager stubbies item which was more popular ten years ago. This is also partly for operational reasons - varieties

Table 3

Items removed from the basket in 2008

\begin{tabular}{|c|c|c|c|}
\hline CPI class & RPI section & Dropped item & Notes \\
\hline 01.1.7 Vegetables & 2129 Other foods & Frozen vegetarian ready meal & $\begin{array}{l}\text { Removed. Very low-weighted item. Ready meals and convenience } \\
\text { foods remain represented in basket by chilled ready meal, frozen } \\
\text { pizza and frozen non-vegetarian meal. Removal allows } \\
\text { improvement of coverage of fresh vegetables. }\end{array}$ \\
\hline
\end{tabular}

02.1.3 Beer

3102 Beer off-sales

Lager stubbies

05.1.2 Carpets and

other floor coverings

05.3.1 Major appliances

and small electrical goods

09.1.5 Repair of audio-visual equipment and related products

4401 Domestic services

TV repair

6102 Maintenance of motor vehicles

Steering lock device

09.1.4 Recording media

6302 CDs and tapes

CD single (top 40)

Washable carpet

Microwave oven

and sports goods

$35 \mathrm{~mm}$ camera film

09.1.4 Recording media

6303 Toys, photographic
Replaced. Stubbies have become difficult to collect and coverage has decreased over 2007. Even in supermarkets it has proven difficult to collect a long run series of prices as pack sizes and alcohol contents vary so greatly. Shelf space has become dominated by regular bottled lager and the new lager item (see Table 2) represents this.

Removed. Spending on washable carpets is low and decreasing. Class is already well represented with a number of other carpet items.

Removed. Very low-weighted item. Removal of this item represents falling expenditure on microwaves over the past decade, due to the fact that unit prices are now so low.

Removed. Low-weighted item. Spending on TV repair has been low and decreasing for a number of years as television prices fall and technology (and reliability) improves. Increasingly, people replace broken televisions rather than fix them, especially with the current dominance of flat panel televisions.

Removed. Spending has decreased in line with improved 'on-board' security of newer cars, for example, automatic steering wheel locks.

Removed. Very low-weighted item within well-represented class. Removal allows introduction of a second CD album item. Popularity of music downloads has led spending on (and shop space devoted to) $C D$ singles to decrease in recent years. Audio CDs remain represented with two $C D$ album items in the basket.

Replaced by portable digital storage media. Low-weighted item within well-represented class. Follows the removal of the $35 \mathrm{~mm}$ camera last year. Spending on camera films has naturally declined with the popularity and affordability of digital cameras and photography. 
of stubbies in supermarkets change frequently and achieving a consistent sample in terms of alcohol content, brand and size can be tricky. It should be stressed that bottled lager is in no way a new item in 2008 - smaller size packs of lager are already priced in the basket and this new item purely represents bulk purchases (20 bottles) in supermarkets

- it is important that the review of the basket considers not just the list of items to be priced, but also where the prices are collected. This is reflected in some changes made to the outlet sample drawn for furniture items (mentioned above) and for fast-food burger takeaway. During 2007, research was undertaken into both of these commodities, seeking to improve representation in the furniture collection and streamline that for fast-food burgers. For furniture, more outlets will be visited in 2008 , with more prices being collected than in the past. For burgers, the review has improved the efficiency of collection and will reduce the number of prices collected in some locations

- finally, as in 2007 , the seasonality of some items within the basket is also reviewed. For example, peaches have historically been collected during the summer months, with prices carried forward out of season. In 2008, attempts will be made to collect peaches in as many months as they are widely available
As noted earlier, it is important that growth in the overall size of the basket is limited each year so that production costs and processing times may be contained. A number of items have therefore been removed from the basket in 2008 to make room for the new additions. Note that the removal of these items from the basket does not necessarily imply that the markets for these goods and services are either very small or declining significantly in recent years:

- some items have been removed to make way for new additions to the basket within the same product grouping. For example, one of the existing fruit juice items is removed in 2008 to be replaced by the pure fruit smoothie, although both products represent pure fruit juice drinks. In other cases, the items have been removed so that new items may be introduced covering distinct markets not previously represented explicitly within the product grouping. For example, $35 \mathrm{~mm}$ camera films have been removed this year so that the market for portable storage media can be represented

- in some cases, a product will still remain represented in the basket even if there is no longer an explicit item. For example, although two king-size cigarette items have been removed from the basket, one new item has been included, which effectively covers the two

Table 4

High-level weights ${ }^{1}$ in RPI since 1987

\begin{tabular}{|c|c|c|c|c|c|c|c|}
\hline RPI group & 1987 & 1992 & 1997 & 2002 & 2006 & 2007 & 2008 \\
\hline Food & 167 & 152 & 136 & 114 & 105 & 105 & 111 \\
\hline Catering & 46 & 47 & 49 & 52 & 50 & 47 & 47 \\
\hline Alcohol & 76 & 80 & 80 & 68 & 67 & 66 & 59 \\
\hline Tobacco & 38 & 36 & 34 & 31 & 29 & 29 & 27 \\
\hline Housing & 157 & 172 & $186^{2}$ & 199 & 222 & 238 & 254 \\
\hline Fuel and light & 61 & 47 & 41 & 31 & 33 & 39 & 33 \\
\hline Household goods & 73 & 77 & 72 & 73 & 71 & 66 & 66 \\
\hline Household services & 44 & 48 & 52 & 60 & 66 & 65 & 64 \\
\hline Clothing and footwear & 74 & 59 & 56 & 51 & 49 & 44 & 42 \\
\hline Personal goods and services & es 38 & 40 & 40 & 43 & 41 & 39 & 41 \\
\hline Motoring expenditure & 127 & 143 & 128 & 141 & 140 & 133 & 133 \\
\hline Fares and other travel costs & s 22 & 20 & 20 & 20 & 19 & 20 & 20 \\
\hline Leisure goods & 47 & 47 & 47 & 48 & 41 & 41 & 38 \\
\hline Leisure services & 30 & 32 & $59^{3}$ & 69 & 67 & 68 & 65 \\
\hline
\end{tabular}

\section{Notes:-}

1 Weights are specified as parts per thousand of the all items RPI.

2 Depreciation costs were added to the housing group in 1995.

3 Foreign holiday costs were added to the leisure services group in 1993, followed by UK holidays a year later.

(a) 
Broadly speaking, weights for services have increased while those for goods have decreased. The most recent weights in the table also illustrate that changes from one year to the next are less marked - for this reason, users should guard against drawing conclusions about evolving spending patterns just from the update of the basket in any one year.

\section{Notes}

1 CPI indices are chain-linked first each January, when weights for CPI classes and higher-level aggregates are updated, and again in February when changes to the basket are introduced and hence weights for individual item indices are reviewed.

2 The CPI is organised according to the internationally agreed COICOP (Classification of Individual Consumption by Purpose) system, as used in the UK National Accounts. The RPI uses a classification system specified by an earlier RPI Advisory Committee, and has evolved gradually over the RPI's long history as a published UK official statistic.

3 RPI weights are based primarily on household spending estimates derived from the Expenditure and Food Survey, and relate to expenditures by private households only, excluding the top 4 per cent of households by income and those pensioner households mainly dependent on state benefits. CPI weights are based on National Accounts estimates of household final consumption consistent with the wider CPI population coverage (all private households, residents of institutional households and foreign visitors to the UK).

4 At the extreme, if price changes for all the possible items that could be selected in a particular group were identical each month, it would be necessary to select only one of the items for inclusion in the basket. Price changes for this one item would be perfectly representative of price changes for the group as a whole.

5 Under CPI regulations, items should be included in the CPI where estimated consumers' expenditure is one part per thousand or more of all expenditure covered by the CPI; based on household final consumption data underpinning calculation of the 2008 CPI weights, this is equivalent to around $£ 680$ million.

6 Coverage extensions during the development of the CPI/HICP mean that long-term comparisons of weights within CPI are more difficult.

\section{CONTACT}

凶elmr@ons.gsi.gov.uk

\section{REFERENCES}

Roe D and Fenwick D (2004) 'The New Inflation Target: the Statistical Perspective', Economic Trends 602, pp 24-46 and at www.statistics.gov.uk/cci/article. $a s p ? i d=688$

Office for National Statistics (2004)

'Consumer price indices - a brief guide' at www.statistics.gov.uk/statbase/ product.asp?vink=62

Office for National Statistics (2007)

'Consumer Price Indices - Technical Manual' at

www.statistics.gov.uk/statbase/

product.asp?vInk $=2328$ 
ANNEX A: CONSUMER PRICES INDEX: REPRESENTATIVE ITEMS IN 2008

\subsection{Food}

01.1.1 Bread and Cereals

Large white loaves - sliced and unsliced

Large wholemeal loaf

Bread rolls

Pitta bread

Flour

Rice

Pasta

Breakfast cereals

Plain biscuits

Corn based snacks

Doughnuts

Sponge cakes

Crackers

Pack of individually wrapped cakes

Frozen pizzas

Fruit pies

Dehydrated noodles / pasta

Chocolate wafers

01.1.2 Meat

Beef

Rump steak

Mince

Frozen burgers

Lamb

Loin chops - home and imported Lamb shoulder

Pork

Lamb leg

Loin chops

Shoulder

Bacon gammon

Bacon back

Chicken

Fresh / chilled whole chicken

Fresh chicken breasts

Frozen chicken breasts

Other Meats

Pork sausages

Cooked meats - eg Ham

Braising steak

Topside

Canned meats

Chicken kievs

Meat pies

Fresh turkey steaks

Frozen chicken nuggets

01.1.3 Fish

White fish fillets

Salmon fillets

Canned tuna

Fish fingers

Frozen prawns

01.1.4 Milk, Cheese and Eggs

Full-fat and semi-skimmed milk - shop-bought and delivered

Fresh cream

Pro-biotic drink

Yoghurt

Cheddar - home-produced and

Chilled pot dessert

imported

Selected speciality cheeses

Fromage frais

Various sized eggs

Other regional cheeses

Cheese spread

01.1.5 Oils and Fats

Margarine / low fat spread

Olive oil

Home-produced and imported butter

01.1.6 Fruit

Cooking apples

Dessert apples

Pears

Bananas

Strawberries

Grapes

Oranges

Grapefruit

Avocado pears

Peaches

Kiwi fruit

Organic fruit

Various canned fruits

Salted peanuts

Small oranges 
01.1.7 Vegetables

White loose and pre-packed potatoes - old and new varieties

Crisps - single and multi-packs

Peppers

Frozen chips

Fresh tomatoes

Cabbage

Cauliflower

Carrots

Mushrooms

Onions

Lettuce

Cucumbers

Canned baked beans

Organic vegetable

Broccoli

Canned tomatoes

Courgettes

Canned sweet corn

Frozen peas

Vegetarian burger/grills

Vegetable pickles

01.1.8 Sugar, Jam, Honey, Syrups, Chocolates and Confectionery

Sugar

Various jams

Ice cream

Gum - chewing and bubble

Various selected popular brands of sweets, chocolates and mints

01.1.9 Food Products (not elsewhere classified)

Soup

Ready cooked meals

Various sauces - eg tomato sauce, mayonnaise

Baby food

01.2 Non - Alcoholic Beverages

01.2.1 Coffee, Tea and Cocoa

Tea bags

Ground coffee

Instant coffee

01.2.2 Mineral Water, Soft Drinks and Juices

Various pure fruit juices

Mineral water

Energy drinks

Squashes

Various fizzy drinks - cans and bottles

Fruit smoothie

\subsection{Alcoholic Beverages (Off Sales)}

02.1.1 Spirits

Whisky

Brandy

02.1.2 Wine

Bottled white wine

Champagne

Bottled cider

02.1.3 Beer

Canned lager

Bottled lager

Vodka

Spirit based drinks

Bottled red wine

Wine purchased in boxes

Fortified wine

Canned draught flow bitter

\subsection{Tobacco}

Selected brand cigarettes

Mentholated cigarettes

Cigars

Vending machine cigarettes

Hand rolling tobacco

\subsection{Clothing}

03.1.2 Garments

Men's Clothing

Suit

Casual coat

Trousers - formal, casual

Fleece

Casual jacket

Jumper

Jeans

Tracksuit bottoms

Various shirts

T-shirts 
Shorts

Underwear

Branded sports sweatshirt

Women's Clothing

Blouses

Dresses

Jeans

Tops

Cardigans

Casual coats

Rainwear

Underwear

Nightwear

Children's Clothing

Schoolwear - trousers, skirts

Jumpers / sweatshirts

Underwear

Pyjamas

Babygro / sleepsuit
Replica football team shirts

Socks

Skirts

Trousers

T Shirt

Shorts

Jackets

Jumpers

Swimwear

Tights

Tops - sports and fashion

Jeans

Jackets

Socks

Trousers

03.1.3 Other Clothing and Clothing Accessories

Men's ties

Knitting wool

Ladies scarves

03.1.4 Cleaning, Repair and Hire of Clothing

Dry-cleaning

\subsection{Footwear Including Repairs}

Shoes - formal, school, casual and fashion

Boots - formal, fashion and outdoor/adventure

Training shoes - sportswear and casual

Sandals

\subsection{Rents}

Private furnished rent

Private unfurnished rent

Local authority rent

UK holiday accommodation (self-

Registered social landlord (RSL) rent catered)

\subsection{Regular Repair and Maintenance of the Dwelling}

04.3.1 Materials for Maintenance and Repair

Ready mixed filler

Wallpaper

Wallpaper paste

Paint

Varnish

Paintbrush

Taps

Ceramic tiles

Hardboard

Softwood

Shower head

Woodscrews

04.3.2 Services for Maintenance and Repair

Fees charged by plumbers, electricians, carpenters and decorators

Hire of domestic steam wallpaper stripper

Gas service charges

\subsection{Water Supply and Misc. Services for the Dwelling}

04.4.1 Water Supply

Average water charges

04.4.3 Sewerage Collection

Average sewerage and environmental charges 
04.5 Electricity, Gas and Other Fuels

04.5.1 Electricity

Average of the electricity companies' tariffs

04.5.2 Gas

Average of the gas companies' tariffs Butane gas

04.5.3 Liquid Fuels

Kerosene

04.5.4 Solid Fuels

Coal

Smokeless fuel

\subsection{Furniture, Furnishings and Carpets}

05.1.1 Furniture and Furnishings

Dining room furniture - eg table, chairs

Bedroom furniture - eg wardrobe, beds, wall hanging mirror

Living room furniture - eg armchair, sofa bed, leather settee, bookcase, table lamp

Kitchen furniture - various kitchen units

Office furniture - home office desk

Outdoor furniture - eg wooden patio set

05.1.2 Carpets and Other Floor Coverings

Selected carpets

Other floor coverings - laminate

Rug

05.2 Household Textiles

Curtains

Fabric roller blind

Duvet

Duvet cover

Bed sheet

Towels

\subsection{Household Appliances}

05.3.1/2 All Major Appliances and Small Electrical Appliances

Cooker - electric

Cooker - gas

Fridge / freezer

Dishwasher

Vacuum clean

Washing machine

Gas Fire

Selected small appliances - eg iron, kettle, fan heater, electric fan

05.3.3 Repair of Household Appliances

Electrical service charges

Charge for various electrical equipment repairs - eg washing machine

05.4 Glassware, Tableware and Household Utensils

Kitchen equipment - eg ovenware, pans, scissors, plastic food container

Tableware - eg crockery set, cutlery set

Glassware - eg tumbler

Flower vase

05.5 Tools and Equipment for House and Garden

Batteries

Light bulbs

Lawn mowers

Other gardening equipment - eg spade

Power tools - eg hammer drill

Door handles

Other tools - eg screwdriver

Aluminium ladders

Power points

\subsection{Goods and Services for Household Maintenance}

05.6.1 Non-Durable Household Goods
Washing powder
Washing-up liquid
Dishwasher tablets
Aluminium foil
Bin liners
Household cleaner 
Fabric conditioner Bleach

Kitchen roll

05.6.2 Domestic Services and Household Services

Domestic help fees Window cleaning fees

Gardeners' fees Nanny fees

06.1 Medical Products, Appliances and Equipment

06.1.1 Pharmaceutical Products

NHS prescription charges Multi-vitamins tablets

Selected medicines - eg indigestion tablets, aspirin, packets of cold/flu drink powder

06.1.2/3 Other Medical and Therapeutic Products

Condoms

Plasters

Spectacle frames

Prescription lenses

Contact lenses

06.2 Out-Patient Services

06.2.1/3 Medical Services and Paramedical Services

Eye test charges

Non NHS medical services - eg physiotherapy, chiropractic medicine

06.2.2 Dental Services

NHS dental charges $\quad$ Private dental exam

06.3 Hospital Services

Hospital charges, including private

surgery fees

Nursing homes

07.1 Purchase of Vehicles

07.1.1a New Cars

New cars

07.1.1b Second Hand Cars

Second hand cars

07.1.2/3 Motorcycles and Bicycles

New motorcycles Second-hand motorcycles

Bicycles

07.2 Operation of Personal Transport Equipment

07.2.1 Spare Parts and Accessories

Selected spare parts and accessories - eg wiper blades, battery, tyres

Satellite navigation system

07.2.2 Fuels and Lubricants

Ultra low sulphur petrol

Motor oil

Ultra low sulphur diesel

07.2.3 Vehicle Maintenance and Repairs

Vehicle service

Labour charge for vehicle repairs

Automatic car wash

Exhaust / brake fitting at fast fit auto

Roadside recovery services centre

07.2.4 Other Services

MOT test fee

Driving lesson fee

Car park charges

Driving test fees

Road tolls

Self-drive car and van hire charges

\subsection{Transport Services}

07.3.1 Passenger Transport by Railway

UK rail fares

Euro Tunnel fares

London transport fares

Other underground/metro fares 
07.3.2 Passenger Transport by Road

Bus fares

Minicab fares

Coach fares

Taxi fares

Charge for home removals

07.3.3 Passenger Transport by Air

Air fares

07.3.4 Passenger Transport by Sea and Inland Waterway

Various ferry and sea fares

08.1 Postal Services

Postal charges

08.2/3 Telephone and Telefax Equipment and Services

Cordless telephones Mobile phone handsets

Fixed line telephone charges - eg line/instrument rentals, call and operator charges

Mobile phone charges - PAYG and

contract

Subscription to the Internet

Cost of directory enquiries

Mobile phone downloads

09.1 Audio-Visual Equipment and Related Products

09.1.1 Reception and Reproduction of Sound and Pictures

DVD player

Audio systems

DVD recorder

Personal MP3 player

Flat panel televisions

Digital (DAB) radio

09.1.2 Photographic, Cinematographic and Optical Equipment

Digital cameras

Disposable cameras

Digital camcorders

09.1.3 Data Processing Equipment

PCs - desktop and laptop PC peripherals

09.1.4 Recording Media

CDs, including CDs purchased over the Internet

Pre-recorded DVDs, including DVDs purchased over the Internet

Recordable CD

Selected CD-ROMs

Recordable DVD

Music downloads

Portable digital storage device

09.1.5 Repair of Audio Visual Equipment and Related Products

Various electrical equipment repair charges - eg PC

\subsection{Other Major Durables for Recreation and Culture}

09.2.1/2 Major Durables for In/Outdoor Recreation including musical instruments

Caravans

Boats

Acoustic guitar

Livery charges

Water sports equipment - eg windsurfing equipment

\subsection{Other Recreational Items, Gardens and Pets}

09.3.1 Games, Toys and Hobbies

Various toys, including some toys purchased over the Internet - eg soft toys,

construction toys, activity toys, dolls

Child's swing

Child's tricycle

Computer games consoles

Computer games

Board games

09.3.2 Equipment for Sport and Open Air Recreation

Sports equipment - eg golf balls, squash racquet, football, fishing rod, football boots

Camping equipment - eg sleeping bag

Barbecue (gas)

09.3.3 Gardens, Plants and Flowers

Selected varieties of plants, bushes, cut flowers, seeds including flowers purchased over the internet 
Compost

09.3.4/5 Pets, Related Products and Services

Cat and dog food - moist and dry

Small pet - eg hamster

Vets' fees

Animal cage

Dog kennel boarding fees

Annual booster injection

\subsection{Recreational and Cultural Services}

09.4.1 Recreation and Sporting Services

Squash court hire

Night-club admission

Slimming clubs

Charges for Exercise classes

Private health club / gym membership

Golf green fees

Ten-Pin bowling session

Fees for leisure evening classes

Horseracing admissions

Admission to football matches, swimming pools, leisure centres, leisure parks and other attractions

09.4.2 Cultural Services

Rentals for DVD and video cassette

recorder

Rentals for various types of TV

Cable TV subscriptions

Rentals for video / DVD films

Digital TV monthly subscription

Film processing

Music downloads

Digital photo processing

Admission to cinemas, theatres, dancing, live music, historic monuments, leisure parks and other attractions

\subsection{Books, Newspapers and Stationery}

09.5.1 Books

Adult and children's fiction and non-fiction paperback and hardback books - including some books purchased over the Internet

09.5.2 Newspapers and Periodicals

National daily newspapers Sunday newspapers

Provincial newspapers

Adults' periodicals

09.5.3/4 Misc. Printed Matter, Stationery, Drawing Materials

Ball point pen

Envelopes

Wrapping paper

Greeting card

Printer paper

Inkjet cartridge

Clear sticky tape

\subsection{Package Holidays}

Package holidays covering a range of foreign destinations, accommodation and holiday types, including late-booked holidays

Package holidays covering a range of UK destinations, accommodation and holiday types

\subsection{Education}

Private School Fees

International Student Fees
Evening Classes

UK university tuition fees

\subsection{Catering Services}

11.1.1 Restaurants and Cafes

Restaurants

Restaurant main course

Restaurant cup of coffee

Pub cold snack

In store cafeteria meal

Take-Away and Snacks

Fish and chips
Restaurant sweet course

Pub hot meals

Burgers in bun - eat in

Muffin

Pasties / savoury pies 


$\begin{array}{ll}\text { Burgers in bun - takeaway } & \text { Kebabs } \\ \text { Sandwiches } & \text { Coffee } \\ \text { Tea } & \text { Caffe latte } \\ \text { Ethnic take-away } & \text { Pizza delivery / takeaway } \\ \text { Soft drinks } & \text { Crisps } \\ \text { Cinema popcorn } & \text { Vending machine fizzy drink } \\ \text { Beer 'On' Sales } & \\ \text { Draught bitter } & \text { Draught lager } \\ \text { Draught stout } & \text { Draught cider } \\ \text { Bottled lager } & \text { Bottled cider } \\ \text { Wines and Spirits 'On' Sales } & \\ \text { Whisky } & \text { Vodka } \\ \text { Wine } & \text { Champagne } \\ \text { Liqueurs } & \text { Spirit based drink } \\ \text { Mixer } & \\ \text { Soft drinks } & \\ \text { Fizzy drinks } & \text { Fruit juice } \\ \text { Bottled mineral water } & \\ \text { Catering } & \\ \text { Cost of catering for a function } & \text { On board catering } \\ \text { 11.1.2 Canteen Meals } & \\ \text { Staff restaurant main course } & \text { Staff restaurant dessert/pudding } \\ \text { Staff restaurant hot snack } & \text { Staff restaurant sandwich } \\ \text { Staff restaurant soft drink } & \\ \text { Prices for school meals } & \\ & \\ \text { Youth Hostel Association } & \text { Halls of residence } \\ \text { Other accommodation services } & \end{array}$

\subsection{Personal Care}

12.1.1 Hairdressing and Personal Grooming Establishments Hairdressing fees Full leg wax

Basic manicure

12.1.2/3 Appliances and Products for

Personal Care

Hair dryer

Electric razor

Toilet roll

Tissues

Disposable nappies

Toothbrush

Tampons

Various cosmetics - eg lipstick, face cream, perfume, mascara, liquid foundation Toiletries - eg toilet soap, toothpaste, deodorant, shower gel, shampoo, hair gel, permanent hair colourant, razor cartridge blades, sunscreen cream / lotion

12.3 Personal Effects (not elsewhere classified)

12.3.1 Jewellery Clocks and Watches

Watch

Various items of personal jewellery

12.3.2 Other Personal Effects

Umbrella

Luggage - trolley case

Handbag

Push chairs

Picture / photo frame

\subsection{Social Protection}

Residential home fees

In home care assistants' fees

Local authority supported residents in retirement homes

Child minder fees

Nursery fees 
Play-group fees

\subsection{Insurance}

12.5.2 House Contents Insurance

Home contents insurance premiums

12.5.3 Health Insurance

Dental insurance

Subscriptions to private medical plans

12.5.4 Transport Insurance

Vehicle insurance

Foreign holidays insurance

12.6 Financial Services (not elsewhere classified)

12.6.2 Other Financial Services

Foreign exchange commission

Unit trust fees and commissions

Money transfer fees

Mortgage arrangement fees
After school club charges

Pet insurance

Various bank charges - eg overdraft fees

Stockbrokers' fees

Credit card fees

12.7 Other Services (not elsewhere classified)

Charges for advertisements in newspapers - local and national

Solicitors' fees - including will drafting fee

Fee for birth and death certificates

Marriage licences

Passport fees

Flower delivery

Cost of basic funeral / cremation

Self-storage fees

Home delivery charges

Surveyors' fee for house valuation 
ANNEX B: RETAIL PRICES INDEX (RPI): REPRESENTATIVE ITEMS IN 2008

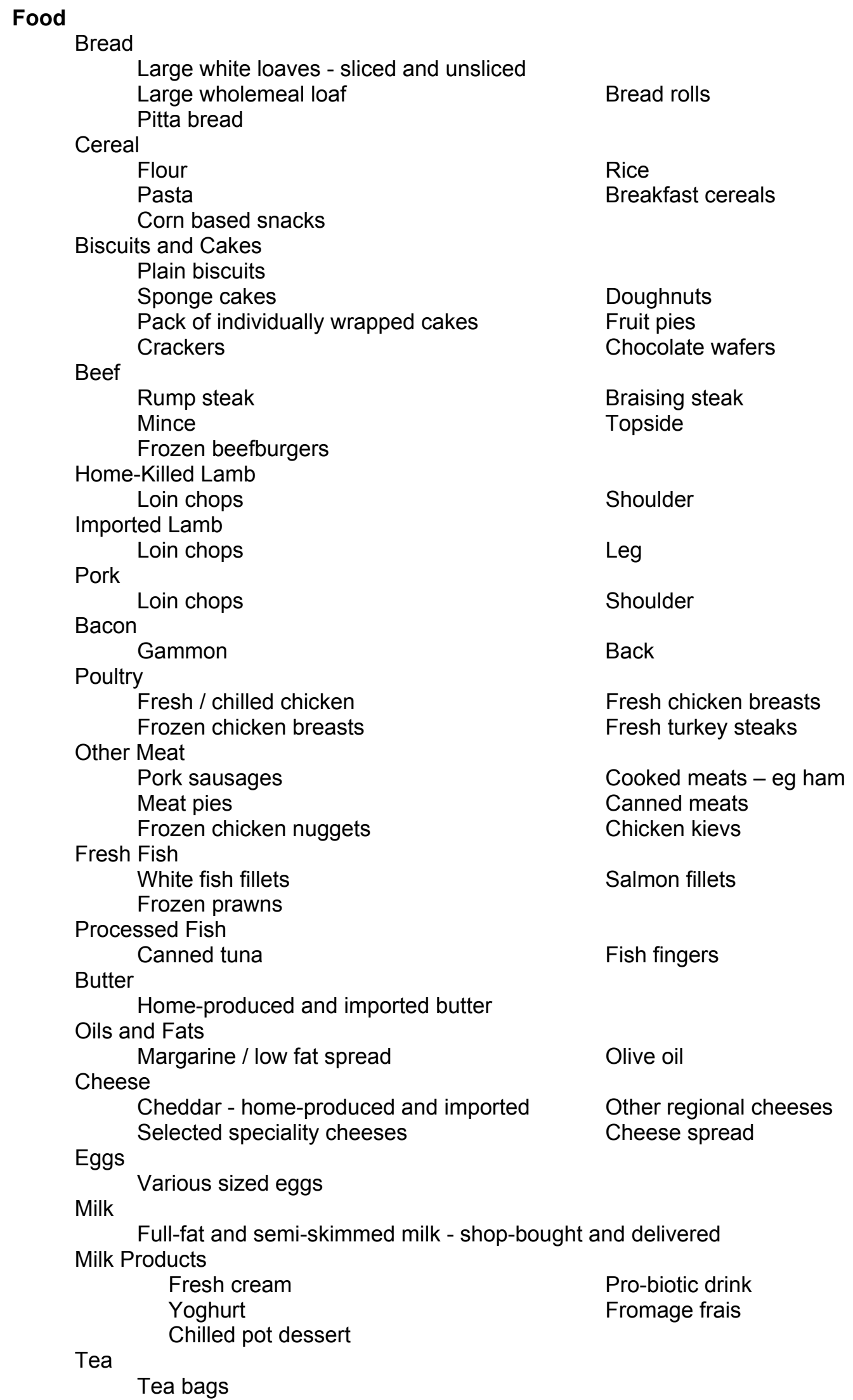


Soft Drinks

Various pure fruit juices

Squashes

Lemonade

Cola

Mineral water

Energy drinks

Various fizzy drinks - cans and bottles

Sugar and Preserves

Sugar

Fruit smoothie

Sweets and Chocolates

Various jams

Various selected popular brands of sweets, chocolates, gum and mints Unprocessed Potatoes

White loose and pre-packed potatoes - old and new varieties

Processed Potatoes

Crisps - single and multi-packs

Frozen chips

Fresh Vegetables

Fresh tomatoes

Cauliflowers

Cabbages

Mushrooms

Carrots

Lettuce

Onions

Courgettes

Broccoli

Processed Vegetables

Canned tomatoes

Cucumbers

Organic vegetable

Peppers

Canned sweet corn

Canned baked beans

Fresh Fruit

Cooking apples

Frozen peas

Pears

Dessert apples

Strawberries

Oranges

Avocado pears

Bananas

Grapes

Grapefruit

Kiwi fruit

Peaches

Small oranges

Organic fruit

Processed Fruit

Various canned fruits Salted peanuts

Other Foods

Soup

Various sauces - eg tomato sauce, mayonnaise, pickle

Ready cooked meals

Other convenience foods - eg frozen pizza, dehydrated noodles / pasta

Ice cream

Coffee and Hot Drinks

Ground coffee

Baby food

Instant coffee

\section{Catering}

Restaurant Meals

Restaurant main course

Restaurant cup of coffee

Pub cold snack

In store cafeteria meal

Fruit juice

On board catering

Canteen Meals

Staff restaurant main course

Staff restaurant hot snack

Staff restaurant soft drink

Take-away and Snacks

Fish and chips

Burgers in bun

Sandwiches

Tea

Ethnic take-away

Soft drinks

Restaurant sweet course

Pub hot meal

Burgers in bun

Fizzy drinks

Bottled mineral water

Muffin

Staff restaurant dessert/pudding

Staff restaurant sandwich

Prices for school meals

Pasties /Savoury pies

Kebabs

Coffee

Caffe latte

Pizza delivery / takeaway

Crisps 


\section{Alcoholic Drink}

Beer 'On' Sales

Draught bitter

Draught Lager

Draught stout

Draught cider

Bottled lager

Bottled cider

Beer 'Off' Sales

Canned lager

Canned draught flow bitter

Bottled cider

Bottled lager

Wines and Spirits 'On' Sales

Whisky

Vodka

Wine

Champagne

Liqueurs

Spirit based drink

Wines and Spirits 'Off' Sales

Whisky

Brandy

Bottled red wine

Wine purchases in boxes

Spirit based drink

Vodka

Bottled white wine

Champagne

Fortified wine

\section{Tobacco}

Cigarettes

Selected brands

Vending machine cigarettes

Other Tobacco

Cigars

Hand rolling tobacco

\section{Housing}

Rent

Private furnished rent

Private unfurnished rent

Local authority rent

Registered Social Landlord (RSL) rent

Mortgage Interest

Average interest payments (estimated/modelled)

Depreciation

Depreciation costs proxy (price index for houses purchased with a mortgage)

Council Tax

Average council tax bills for households in Great Britain

Average rates bills in Northern Ireland

Water and Other Charges

Average water charges

Average sewerage and environmental charges

Repair and Maintenance Charges

Fees charged by plumbers, electricians, carpenters and decorators

Gas service charges

DIY Materials

Ready mixed filler

Wallpaper

Wallpaper paste

Paint

Varnish

Paint brush

Various tools - eg hammer drill, screwdriver

Aluminium ladder

Door handle

Taps

Power point

Shower head

Pieces of timber

Ceramic tiles

Hire of domestic steam wallpaper stripper Woodscrews

Dwelling Insurance and Ground Rent

Dwelling insurance premiums of selected companies

Ground rent proxy (price index for houses purchased with a mortgage)

\section{Fuel and Light}

Coal and Solid Fuels 
Coal

Smokeless fuel

Electricity

Average of the electricity companies' tariffs

Gas

Average of the gas companies' tariffs

Oil and Other Fuels

Butane gas

Kerosene

\section{Household Goods}

Furniture

Dining room furniture - eg table, chairs

Bedroom furniture - eg wardrobe, beds

Living room furniture - eg armchair, sofa bed, leather settee, bookcase, table lamp

Kitchen furniture - various kitchen units

Office furniture - home office desk

Outdoor furniture - eg wooden patio set

Furnishings

Selected carpets

Rug

Fabric roller blind

Other floor coverings - laminate

Duvet cover

Curtains

Towels

Duvet

Bed sheet

Electrical Appliances

Cooker - electric

Washing machine

Fridge / freezer

Dishwasher

Vacuum cleaner

Cordless telephone

Mobile phone handsets

Selected small appliances - eg iron, kettle, fan heater, fan

Personal appliances - eg hair dryer, electric razor

Other Household Equipment

Cooker - gas

Gas fire

Kitchen equipment - eg ovenware, pans, scissors, plastic food container

Tableware - eg crockery set, cutlery set

Glassware - eg tumbler

Household Consumables

Washing powder

Washing-up liquid

Dishwasher tablets

Aluminium foil

Kitchen roll

Light bulbs

Bin liners

Toilet rolls

Bleach

Ball point pen

Envelopes

Fabric conditioner

Household cream cleaner

Printer paper

Pet Care

Clear sticky tape

Wrapping paper

Greeting card

Inkjet cartridge

Batteries

Cat and dog food - moist and dry

Small pet - eg hamster

Animal cage

Vets' fees

Annual booster injection

Dog kennel boarding fees

\section{Household Services}

Postal Charges

Charges for letters, parcels, postal orders

Telephone Charges

Fixed line telephone charges - eg line/instrument rentals, call and operator charges

Mobile phone charges - PAYG and contract Mobile downloads

Subscription to the Internet

Domestic Services

Domestic help fees

Childminder fees

Playgroup fees

Gardeners' fees

Cost of directory enquiries

In home care assistant fees

Nanny fees

After school club charges

Window cleaning 
Dry cleaning charges

Home delivery charges

Self-storage fees

Charge for various electrical equipment repairs - eg washing machine, PC

Electrical service charges

Cost of catering for a function

Driving lesson fee

Charge for home removals

Fees and Subscriptions

Trade unions and professional organisations subscriptions

Estate agents' fees

House conveyancing fees

Charge for home buyers' survey

Fee for birth and death certificates

Passport fee

Money transfer fees

Driving test fees

Evening classes

UK University tuition fees

Pet insurance

Mortgage arrangement fees

Charges for advertisements in newspapers - local, national

\section{Clothing and footwear}

Men's Outerwear

Suit

Trousers - formal, casual

Fleece

Jumper

Tracksuit bottoms

Shorts

Branded sports sweatshirt

Women's Outwear

Blouses

Dresses

Jeans

Tops

Cardigan

Casual Coat

Rainwear

Children's Outerwear

Schoolwear - trousers, skirts

Jeans

Jackets

Trousers

Other Clothing

Underwear - eg pants and bra

Surveyors' fee for house valuation

Home contents' insurance premiums

Marriage licences

Various bank fees - eg overdraft charges

Foreign exchange commission

Private school fees

Solicitors' fees - including will drafting

Cost of basic funeral / cremation

Nursery fees

Casual Coat

Casual jacket

Jeans

Various shirts

T-shirts

Replica football team shirt

Skirts

Trousers

T-shirt

Shorts

Jackets

Jumper

Swimwear

Tops - sports and fashion

Jumpers/sweatshirts

Babygro/sleepsuit

Socks

Tights

Tie

Nightwear - eg nightdress/pyjamas

Knitting wool

Footwear

Shoes - formal, school, casual and fashion

Boots - formal, fashion and outdoor/adventure

Training shoes - sportswear and casual

Sandals

\section{Personal Goods and Services}

Personal Articles

Umbrella

Handbag

Watch

Prescription lenses

Luggage - trolley case

Spectacle frames

Contact lenses

Flower vase

Picture / photo frame

Wall hanging mirror

Various items of personal jewellery 
Chemists' Goods

NHS prescription charges Multi-vitamins tablets

Condoms

Tampons

Disposable nappies

Tissues

Selected medicines and surgical goods - eg indigestion tablets, pain killer tablets, packets

of cold/flu drink powder, plasters

Toiletries - eg toilet soap, toothpaste, toothbrush, deodorant, shower gel, shampoo, hair

gel, permanent hair colourant, razor cartridge blades, sunscreen cream / lotion

Various cosmetics - eg lipstick, face cream, perfume, mascara, liquid foundation

Personal Services

Hairdressing charges

Full leg wax

Basic manicure

Eye tests charges

Dental charges

Subscriptions to private medical plans

Dental insurance

Non NHS medical services - eg physiotherapy, chiropractic medicine

Residential and nursing home fees Slimming club fees

Flower delivery

\section{Motoring Expenditure}

Purchase of Motor Vehicles

Second-hand cars

Proxy for new cars

New motorcycles

Second-hand motorcycles

Caravans

Maintenance of Motor Vehicles

Car service

MOT test fee

Roadside recovery services

Automatic car wash

Exhaust / brake fitting at fast fit auto centre

Hourly labour charge for car mechanical repairs

Selected spare parts and accessories - eg wiper blade, battery, tyres

Petrol and Oil

Ultra low sulphur petrol

Ultra low sulphur diesel

Motor oil

Vehicle Tax and Insurance

Vehicle excise duty

Selection of premiums charged by a sample of motor insurance companies

\section{Fares and Other Travel Costs}

Rail Fares

UK rail fares London Transport fares

EuroTunnel fares Other underground/metro fares

Bus and Coach Fares

Fares charged by principal bus and coach operators

Other Travel Costs

Taxi fares

Self-drive car and van hire charges

Air fares

Minicab fares

Other means of transport - eg bicycles, boats

Various ferry and sea fares

Road tolls

Push chairs

\section{Leisure Goods}

Audio-visual Equipment

Flat panel televisions

Digital radio

Car park charges

Personal MP3 player

Audio systems

Satellite navigation system

DVD player

DVD recorder

PCs - desktop and laptop

$\mathrm{PC}$ peripherals

CDs and Tapes

Pre-recorded DVDs, including DVDs purchased over the Internet

CDs, including CDs purchased over the Internet

Recordable CD

Recordable DVD

Selected CD-ROMs

Music downloads 
Toys, Photographic and Sports Goods

Various toys, including some toys purchased over the Internet - eg soft toys, construction toys, activity toys, dolls

Board games

Computer games

Computer games consoles

Digital camcorder

Digital camera

Film and digital processing

Disposable cameras

Child's swing

Acoustic guitar

Sleeping bag

Child's tricycle

Barbecue (gas)

Sports equipment - eg golf balls, squash racquet, football, fishing rod, football boots

Water sports equipment - eg windsurfing equipment

Portable digital storage device

Books and Newspapers

Adult and children's fiction and non-fiction paperback and hardback books - including

some books purchased over the Internet

National daily newspapers

Sunday newspapers

Provincial newspapers

Adults' periodicals

Gardening Products

Compost

Selected varieties of plants, bushes, cut flowers, seeds including flowers purchased over the internet

Garden sundries - eg garden spade

Lawnmowers

\section{Leisure Services}

TV Licences and rental

Television licence fees

DVD and video cassette recorder rental

Digital television monthly subscription fees

Entertainment and Recreation

Squash court hire

Charges for exercise classes

Ten-pin bowling session

Golf green fees

Rentals for various types of TV

Rentals for DVD films

Cable TV subscriptions

Admission to cinemas, theatres, dancing, live music, football matches, historic

monuments, leisure parks and other attractions, swimming pools, leisure centres

Foreign Holidays

Package holidays covering a range of foreign destinations, accommodation and holiday types, including late-booked holidays

Holiday insurance

UK Holidays

Fees for leisure evening classes

Private health club / gym membership

Horse racing admissions

Livery charges

Package holidays covering a range of UK destinations, accommodation and holiday types 